\title{
EL REPERTORIO POLIFÓNICO DE LA COLEGIATA DE ORIHUELA SEGÚN UN INVENTARIO DE MITAD DEL SIGLO XVI ${ }^{1}$
}

\author{
Esperanza Rodríguez García \\ Universidad de Manchester
}

\begin{abstract}
Resumen:
La información sobre la capilla musical de la colegiata de Orihuela es escasa. Sin embargo, la existencia de un inventario de música polifónica compilado antes de 1562 muestra el repertorio polifónico de la capilla a mitad del siglo XVI. El contenido del inventario plantea algunas cuestiones generales sobre la música en las instituciones eclesiásticas españolas. De un lado, la elevada cantidad de música impresa suscita reflexiones sobre el papel de la imprenta musical en España; de otro, la alta proporción de piezas no españolas muestra la penetración del repertorio internacional en las capillas españolas. El apéndice final proporciona datos sobre algunos de los maestros de capilla de la colegiata y catedral de Orihuela en el siglo XVI.
\end{abstract}

Palabras Clave:

Catedral de Orihuela, inventario de libros de música, siglos Xv y xvI, maestros de capilla de la catedral de Orihuela.

Abstract:

Information about the musical chapel in the collegiate church of Orihuela is scarce. Nonetheless the existence of an inventory of polyphonic music dated before 1562 sheds some light on the repertory of the musical chapel in the mid-sixteenth century. The content of the inventory raises, in addition, some general questions regarding the repertory of Spanish ecclesiastical institutions in the mid-sixteenth century. On the one hand, the large number of printed items poses questions on the role of printing in Spain; on the other hand, the high proportion of non-Spanish works gives proof of the penetration of the international repertory in Spanish ecclesiastical institutions. The appendix gives new data of some chapelmasters of Orihuela collegiate church and cathedral in the sixteenth century.

Key Words:

Orihuela Cathedral, music book inventory, 15th and 16th centuries, chapelmasters of Orihuela Cathedral

1 Desearía agradecer la ayuda económica prestada por el "Arts and Humanities Research Council” de Gran Bretaña y la University of Manchester, sin la cual este artículo no hubiese sido posible. Mi gratitud se extiende a diferentes personas que han contribuido a mejorarlo sustancialmente. Juan Ruiz, David Fallows, Maricarmen Gómez y Josep A. Alberola aportaron numerosas sugerencias tras la lectura de versiones previas del mismo; Mariano Cecilia, archivero de la Catedral de Orihuela, y Juan Pérez Berná proporcionaron información indispensable para su realización. 
La colegiata de Orihuela fue erigida en 1413 sobre la iglesia arciprestal del Salvador y Santa María. En 1564, la diócesis de Orihuela se segregó de la de Cartagena y la colegiata fue elevada a catedral. La práctica musical experimentó una transformación radical entre esos dos hitos: si en 1413 no se previó dotación musical específica (lo que en la práctica significaba el uso prioritario de música monódica), en 1564 se produjo la institucionalización de una capilla musical para la interpretación de la polifonía.

Aunque existen referencias a la polifonía en ceremonias extraordinarias desde 1424, la escasa información conservada no permite conocer cómo y cuándo su uso se hizo extensivo a la práctica cotidiana. El Archivo de la Catedral de Orihuela (E-ORI) custodia los documentos fundamentales de la colegiata (las bulas fundacionales y los estatutos), pero la información sobre su funcionamiento diario ha sufrido peor suerte. Los libros de actas capitulares sólo se conservan desde $1554^{2}$. Entre los libros de fábrica, depositados en el Archivo Histórico de Orihuela (AHO) sólo se encuentra disponible el libro correspondiente a los años 1555 y $1556^{3}$.

Sin embargo, dos documentos generados con motivo de la elevación de la colegiata a catedral -un memorial sobre la situación de la colegiata en 1563 y el informe de ejecución de las bulas catedralicias en 1564- permiten constatar que la práctica de la polifonía era habitual al final de la época colegial. Además, un inventario de música realizado antes de 1562 nos revela el repertorio polifónico disponible a mediados de la centuria. Dos rasgos del inventario, la alta proporción de volúmenes impresos y la elevada presencia de compositores no españoles, refuerzan las conclusiones de recientes líneas de investigación sobre la música en las instituciones eclesiásticas españolas en el Renacimiento, que señalan la importancia de la música impresa y del repertorio internacional. A modo de apéndice se ha incluido un apartado con datos sobre los maestros de capilla de la colegiata y la catedral durante el siglo XVI al que se remite siempre que se cite un maestro de capilla (en adelante, $\mathrm{MC})$.

Antes de presentar estos documentos, procederé a realizar una breve introducción sobre la historia y la estructura de la colegiata de Orihuela. Aunque no existen monográficos sobre la colegiata, ésta se ha estudiado en la amplia bibliografía sobre la catedral ${ }^{4}$. La última y más exhaustiva historia de la

2 E-ORI, Actas capitulares, tomo 2 (1554-1568), sig. 870.

3 Archivo Histórico de Orihuela, Libro de fábrica de la catedral de Orihuela (1555-1556), sig. D 319-4. El libro más antiguo conservado data de 1534, pero su estado es tan precario que no se permite su consulta. Archivo Histórico de Orihuela, Libro de fábrica de la catedral de Orihuela (1534-1583), sig. D 1802.

4 E-ORI, José de Alenda, Manual para el archivero de la Sta yglesia de Origuela, 1607, sig. 1091a [transcripción fragmentaria en: Pérez Berná, Juan: La capilla de música de la catedral de Orihuela: las composiciones en romance de Mathías Navarro (ca. 1666-1727). Tesis doctoral; Universidad de Santiago de Compostela, 2008, pp. 922-30; E-ORI, MiRAVETE DE MASERES, Gonzalo: Diccionario primero de acuerdos capitulares, 1783, sig. 926. GEA, J. Rufino: Páginas de la historia de Orihuela. El pleito del Obispado. 1383-1564 [original/ Orihuela, s.n.,1900], facsímil/Valencia, Librerías "París-Valencia", 1995; BAUTISTA VILAR, Juan: Orihuela, una ciudad valenciana en la España moderna: Historia de la ciudad y obispado de Orihuela. Murcia, Patronato “Ángel García Rogel”, 1981; VIDAL Tur, Gonzalo: Un obispado español. El de Orihuela-Alicante. Alicante, Diputació provincial, 1979; Mansilla Reoyo, Demetrio: Geografía eclesiástica de España. Estudio histórico-geográfico de las diócesis. Roma, Instituto Español de Historia Eclesiástica, 1994; OsedA NieTo, José: El patrimonio de la catedral de Orihuela gobierno y administración de un edificio religioso en el Antiguo Régimen. Orihuela, s.n., 1997. 
institución hasta la fundación de la catedral es ofrecida en la tesis doctoral de Antonio Carrasco, $L a$ ciudad de Orihuela y el pleito del obispado en la Edad Moderna ${ }^{5}$.

La fundación de la colegiata de Orihuela fue sancionada por el papa cismático Benedicto XIII, quien firmó las bulas el 13 de abril de 1413 a petición del rey Fernando I de Aragón ${ }^{6}$. La erección fue confirmada en $1422^{7}$. La colegiata supuso el primer logro en la reivindicación de las autoridades oriolanas para conseguir una diócesis independiente que se ajustara a la demarcación jurisdiccional de la zona. El problema había comenzado en 1305. Hasta ese momento, Orihuela estaba integrada en la diócesis de Cartagena a efectos eclesiásticos y en el Reino de Murcia (incluido en la Corona de Castilla) a efectos administrativos. Los límites de estas dos unidades de organización coincidían exactamente. Pero a partir de dicha fecha, Orihuela pasó a depender administrativamente de la Corona de Aragón, convirtiéndose en la sede de la Gobernación meridional del Reino de Valencia. Sin embargo, su vinculación eclesiástica con la diócesis de Cartagena se mantuvo intacta. El asunto se complicó todavía más en 1492, cuando la diócesis de Cartagena, que dependía directamente de Roma, pasó a ser sufragánea del recién creado arzobispado de Valencia. Esta adscripción múltiple provocó un largo período de enfrentamientos en la vida política, religiosa y económica, conocido con el nombre de "El pleito del obispado". Desde su incorporación a la Corona de Aragón, Orihuela trató de obtener su propia diócesis (la primera petición se produjo en 1383). Por su parte, el obispado de Cartagena se opuso. Los reyes aragoneses respaldaron las reivindicaciones oriolanas, los reyes Carlos I y Felipe II decidieron según la coyuntura del momento y los papas intentaron conciliar las distintas posiciones. El conflicto sólo finalizó tras la creación de la nueva diócesis en 1564.

El paso siguiente tras la fundación de la colegiata fue la creación de un vicariato en 1430. En 1442 se aprobó un nuevo obispado en Orihuela, que fue anulado en 1443. En 1451 el vicariato fue también anulado. En 1456, el papa valenciano Calixto III confirmó definitivamente el vicariato. Medio siglo después, en 1510, el papa Julio II, a petición de Fernando el Católico, decretó la creación del obispado de Orihuela, aunque unido al de Cartagena sub uno pastore ${ }^{8}$. En medio de graves disturbios, el obispado no llegó a establecerse y las bulas fueron definitivamente revocadas en $1521^{9}$.

Finalmente, en 1563, Felipe II consideró improrrogable la creación de la diócesis de Orihuela, arguyendo diversos factores como el gran tamaño de la diócesis de Cartagena, el elevado número de población morisca con necesidades especiales, la coexistencia de diferentes leyes e

5 Carrasco Rodríguez, Antonio: La ciudad de Orihuela y el pleito del obispado en la Edad Moderna. Alicante, 2001 (Biblioteca Virtual Miguel de Cervantes). <http://www.cervantesvirtual.com/FichaObra.html?Ref=6199\&ext=pdf >.

6 E-ORI, Bula de Benedicto XIII de creación de la colegiata, 1413, sig. 1112, pergamino 1 (transcrita y traducida: en Carrasco Rodríguez, Antonio: La ciudad de Orihuela, op. cit., pp. 419-421).

7 Carrasco Rodríguez, Antonio: La ciudad de Orihuela, op. cit., pp. 23-27.

8 Íbid., pp. 27-41.

9 Entre otros conflictos, en 1513 las autoridades murcianas desviaron el cauce del río Segura, provocando inundaciones y la pérdida de las cosechas; en 1518 hubo invasiones murcianas en Orihuela, que fue incendiada y saqueada. Además, el movimiento reivindicativo oriolano corrió una suerte paralela a los agermanados, con cuyas posiciones se alineó. Íbid., pp. 42-78. 
idiomas y los continuos problemas fronterizos. Un año más tarde el papa Pío IV firmó las bulas correspondientes ${ }^{10}$.

En cuanto a la estructura de la colegiata, la bula de 1413 instituyó trece canonjías, que incluían las tres dignidades (Prepositus, Sacrista y Precentor) y diez beneficios (cuatro presbíteros hebdomadarios, un diácono, un subdiácono, y cuatro niños con inclinación al estado eclesiástico o pueri pro clericalibus seu minoribus). Se mantuvieron, además, tres de las capellanías de patronato laico existentes anteriormente $^{11}$. Los estatutos, redactados en 1424, señalaban como fiestas de doble rito la Navidad, la Epifanía del Señor, el Jueves Santo, el Domingo de Resurrección, Pentecostés, Corpus Christi, la Asunción del Señor, Todos los Santos y la Inmaculada Concepción). Además, la misa diaria para los difuntos y la misa dedicada a la Virgen los sábados eran consideradas de primera importancia ${ }^{12}$.

Los estatutos no establecieron ningún cargo relacionado con la música ${ }^{13}$. Sin embargo, mencionan la práctica diaria del canto llano, indicando que los miembros del cabildo debían participar en las ceremonias de la colegiata cantando responsorios y salmos ${ }^{14}$. No hay referencias explícitas ni indicios que permitan suponer la participación musical de los niños en estas celebraciones ${ }^{15}$.

Sorprendentemente, el documento prescribe el uso de la polifonía como recurso excepcional en la celebración de Corpus Christi, la festividad oficiada con mayor boato en la "catedral". En cada uno de los días de la semana posterior se realizaba una procesión interna en la "colegiata". Cuando la comitiva llegaba al altar mayor se interpretaba en polifonía el Pange lingua ["cantant los chantres o cantors a cant de orgue lo pange lingua"]. La función de los niños (diferenciados entre "infants de choro" y "escolans") consistía exclusivamente en llevar los cirios y el incensario ${ }^{16}$. Además, el día de la octava del Corpus había una procesión externa, en la que participaban 'orguens trompetes y musica' pagados por la cofradía del Corpus. En la capilla del Corpus (dentro de la colegiata) se cantaba el Pange lingua en alternatim ["lo preste traura lo corpus del reliquiari e tret aquell lo ponrra en les mans e començara en lo to de pange lingua lo vers que diu, Verbum panem verum, verbo carnem efficit e acabant lo preste

10 Íbid., pp. 79-300.

11 Sólo hubo tres modificaciones posteriores de esta estructura. En primer lugar, antes de la mitad del siglo xv, se estableció una nueva capellanía de patronato laico; posteriormente, en 1510, se instituyó una cuarta dignidad, el arcedianato, pagada con las rentas de otra iglesia de Orihuela (la de las Santas Justa y Rufina); por último, en 1559 se suprimió una canonjía, en aplicación de la bula del papa Paulo iv, mediante la cual las rentas de una canonjía en todas las colegiatas y catedrales españolas fueron aplicadas a la Inquisición. Íbid., pp. 24-26, 345-46. Véase también: Pérez BeRnÁ, Juan: La capilla de música, op. cit., pp. 9-10.

12 E-ORI, Estatutos de la Santa Iglesia de Orihuela en su estado colegial, 1424, sig. sin registrar, fols. $8 \mathrm{v}-11 \mathrm{v}$.

13 Pérez Berná, Juan: La capilla de música, op. cit., p. 35, indica que hay un apartado referido al organista.

14 E-ORI, Estatutos de la Santa Iglesia de Orihuela en su estado colegial, 1424, sig. sin registrar, fols. 11v, 28v, 32v.

15 R. Strohm, sin embargo, indica que la participación de los niños en el canto llano fue común durante la Edad Media, mientras que en polifonía fue habitual a partir de la segunda década del siglo xv. STRoHm, Reinhard: The Rise of European Music, 1380-1500. Cambridge, Cambridge University Press, 1993, pp. 279, 287-291. En territorio español, una de las noticias más tempranas que señalan que los niños aprendían polifonía se recoge en la catedral de Toledo en 1418. ReYnAUD, François: $L a$ polyphonie tolédane et son millieu. Des premiers témoignage aux environs de 1600. Paris, CNRs Éditions, 1996, p. 99.

16 E-ORI, Estatutos de la Santa Iglesia de Orihuela en su estado colegial, 1424, sig. sin registrar, fol. 50v. Por el contrario, en la procesión del Corpus Christi de 1440 en Sevilla seis mozos de coro cantaron polifonía. Archivo de la Catedral de Sevilla, sección IV, libro 13, fols. 44v-45v. Citado en: RuIz Jiménez, Juan: La librería de canto de órgano: creación y pervivencia del repertorio del Renacimiento en la actividad musical de la catedral de Sevilla. Granada, Consejería de Cultura, 2007 , p. 279. 
les damunt dites paraules los cantors a cant dorgue acabaran lo vers"] ${ }^{17}$. Dado el carácter extraordinario de las celebraciones, los cantores eran seguramente contratados para la ocasión.

La presencia de música polifónica en fecha tan temprana acaso sirvió de acicate para la creación de una capilla musical permanente ${ }^{18}$. Cuando la práctica polifónica fue ganando importancia (aunque la monodia siguió siendo predominante) ${ }^{19}$, los cabildos se vieron obligados a crear estructuras con funciones específicamente musicales ${ }^{20}$, así como a orquestar fórmulas para su mantenimiento económico $^{21}$. La institucionalización posterior reguló una práctica ya existente y sirvió, además, para racionalizan los costes económicos derivados de ella ${ }^{22}$. Las capillas de música se fueron consolidando en España a lo largo del siglo $\mathrm{Xv}^{23}$. En la catedral de Murcia (sede de la diócesis de Cartagena y, por tanto, modelo de la colegiata de Orihuela) se tiene conocimiento del uso de la polifonía desde la primera mitad del siglo Xv y de la consolidación de una capilla musical con un MC así como con varios cantores en $1477^{24}$. No sería, pues, extraño que la colegiata de Orihuela hubiese tenido también una capilla musical en fecha temprana, aunque su institucionalización no ocurrió hasta 1564, cuando se fundó la catedral.

17 Íbid., fols. 51v-52r

18 No existe ningún monográfico dedicado a la música en la colegiata de Orihuela. Los trabajos que estudian la capilla de música en la época catedralicia hacen someras referencias a la etapa previa. Entre ellos cabe citar: Blasco, Julio y Pedrell, Felipe: "Juan Ginés Pérez", en: Pedrell, Felipe, ed.: Hispaniae Schola Musica Sacra. Juan Ginés Pérez. Vol. 5, Barcelona, Juan Bta. Pujol, 1896, IXIV; el catálogo musical del archivo realizado por J. Climent y capítulos en obras generales de este mismo autor (CLIMENT, José: Fondos musicales de la Región Valenciana rv. Catedral de Orihuela. Valencia, Generalitat Valenciana, 1986; ID., 'Las capillas musicales', en: Badenes, Gonzalo, ed.: Historia de la música de la Comunidad Valenciana. Valencia, Instituto de Musicología, Institución Alfonso el Magnánimo, Diputación Provincial de Valencia, Prensa valenciana, 1992, p. 147; ID.: "La catedral de Orihuela", en: CARRASCO, Antonio, ed.: La luz de las imágenes. Orihuela. Valencia, Generalitat Valenciana, 2003, pp. 89-115); los artículos de P. Capdepón, dedicados al siglo XVII (CAPDEPÓN Verdú, Paulino: "Matías Navarro, maestro de la Catedral de Orihuela”, en Revista de Musicología, 21 (1998), pp. 169-96; ID.: "Organistas de la Catedral de Orihuela en el siglo xvII", en Nassarre, 18 (2002), pp. 451-478); el trabajo de E. Rodríguez sobre el compositor y maestro de capilla de la catedral de Orihuela Ginés Pérez (RodRíGuEz, Esperanza: Ginés Pérez: set motets inèdits. Valencia, Tritó/Institut Valencià de la música, 2007); y la tesis doctoral de Pérez BERNÁ, Juan: La capilla de música, op. cit. .

19 Asensio Palacios, Juan Carlos: "El canto llano en la España del siglo xvi. De olvidos y protagonismos", en: GRIFFITHS, John; y SuÁrez-PAJares, Javier, eds.: Políticas y prácticas musicales en el mundo de Felipe II. Madrid, ICCMU, 2004, pp. 253-284, 253-254.

20 CARreras, Juan J.: "La capilla en la corte. Perfil musical y contexto historiográfico de una institución”, en: CARRERAs Juan J.; y García García, Bernardo, eds.: La Capilla Real de los Austrias. Música y ritual de la corte en la Europa moderna, Madrid, Fundación Carlos de Amberes, 2001, p. 24.

21 Alberola Verdú, Josep A.: La música a la col-legiata de Xàtiva. Tesis doctoral; Universitat de València, 2007, pp. 86-88.

22 J. Ruiz Jiménez analiza la cuestión económica respecto de los ministriles, aunque la conclusión puede extrapolarse perfectamente a otros colectivos como los cantantes o el maestro de capilla. RuIZ JiMÉNEZ, Juan: "Ministriles y extravagantes en la celebración religiosa", en: GrifFiths, John; y Suárez-PaJAres, Javier, eds.: Políticas y prácticas musicales, op. cit., pp. 199-239, en p. 201. J. Suárez-Pajares considera que la tendencia a incluir al personal relacionado con la música entre los beneficiados pagados de la mesa tiene que ver con la valoración de la música polifónica como un elemento esencial del culto. Ello no explica la decisión de algunos cabildos de tener diferentes grupos de cantores pagados los unos con rentas de la mesa y los otros de la fábrica. Así ocurrirá en Orihuela cuando se funde la catedral (véase más adelante) o en Toledo como J. Suárez-Pajares menciona. SuÁREzPAJARES, Javier: "Dinero y honor: aspectos del magisterio de capilla en la España de Francisco Guerrero", en: GRIFFITHS, John; y Suárez-PaJares, Javier, eds.: Políticas y prácticas musicales, op. cit., pp. 149-197, en p. 171, nota al pie 114.

23 Véase, por ejemplo, los casos de Sevilla (RuIz JiménEz, Juan: La librería de canto de órgano, op. cit., pp. 75-81, 278280) y Toledo (ReYnaud, François: La polyphonie tolédane, op. cit., pp. 2-5, 74-75).

24 Prats Redondo, Consuelo: "Murcia", en: CASAREs, Emilio, ed.: Diccionario de la música española e hispanoamericana. Madrid, SGAE, 1999-2002, 10 vols., [en adelante citado como $D M E H$ ], vol. 7, pp. 889-896, en 893. Quiero agradecer a Consuelo Prats que haya compartido amablemente conmigo información no publicada sobre la catedral de Murcia. 
La primera noticia sobre un miembro de la capilla de música procede de fuentes secundarias, cuya procedencia no he podido localizar. Michael Noone indica que Pedro de Ribera fue MC de la colegiata de Orihuela antes de $1535^{25}$. Las referencias posteriores proceden de las cuentas de fábrica de la colegiata y se reducen a los años 1555 y 1556. Aunque los datos permiten atestiguar la existencia efectiva de músicos en la colegiata, no son suficientes para obtener una idea del nivel de los salarios. En octubre de 1555 el organista Gaspar Joan del Río recibió de la fábrica 6 libras (£), 13 sueldos (s) y 4 dineros (d), como pago del primer cuatrimestre de su salario anual ${ }^{26}$. En el caso de que no se le hubiera descontado nada por faltas de asistencia, el salario anual sería de unas $20 £^{27}$. Un cantor, Cristòfol Martí, obtuvo $5 £$ $10 \mathrm{~s} 8 \mathrm{~d}$ por seis meses y veinte días de trabajo, que serían aproximadamente unas $12 £$ anuales ${ }^{28}$. Por último, el Mc Francesc Joan Embite recibió 15£ "per raho del temps que servi de mestre de capella en lo any MDLiiii" (apéndice 1) ${ }^{29}$. La cantidad, exigua comparada con el estipendio del organista, no puede considerarse indicativa del salario del MC. En primer lugar, no se sabe si se trata del salario anual, ya que Embite pudo trabajar menos de un año completo (la expresión "per rahó del temps" es ciertamente vaga). No parece tampoco que se trate de una cantidad cuatrimestral, forma habitual en el sistema de pago pero que siempre se indica. Embite tenía uno de los beneficios de la catedral por lo que parece lógico pensar que su sueldo como MC fuese un complemento de las colaciones que recibía ${ }^{30}$.

La constatación de que existía una capilla musical consolidada se halla en los dos informes previos a la elevación de la catedral mencionados en la introducción ${ }^{31}$.

El primer documento es el memorial de Francisco de Castilla realizado en 1563. Fue encargado por Felipe II para intentar determinar con certeza la estructura y las rentas reales de la colegiata. El informe, basado en entrevistas, es bastante impreciso. Sin embargo, todos los capitulares entrevistados

25 Noone, Michael: "Ribera, Bernardino de", en $D M E H$, vol. 9, pp. 171-72. Véase apéndice 1.

26 Gaspar del Río fue organista de la colegiata de Játiva entre 1574 y 1575, cuando murió. Alberola Verdú, Josep A.: La música a la col-legiata de Xàtiva, op. cit., p. 210. En 1571 estaba todavía en Orihuela, como se infiere de un pago que se le hizo por un concepto indeterminado a principios de 1571. E-ORI, Actas capitulares, tomo 7 (1569-1608), sig. 875, fol. 26r, 11-01-1571. $10-1555$

27 Archivo Histórico de Orihuela, Libro de fábrica de la catedral de Orihuela (1555-1556), sig. D 319-4, fol. 177v, 2405-1556

28 Archivo Histórico de Orihuela, Libro de fábrica de la catedral de Orihuela (1555-1556), sig. D 319-4, fol. 184v, 2506-1556.

29 Archivo Histórico de Orihuela, Libro de fábrica de la catedral de Orihuela (1555-1556), sig. D 319-4, fol. 191v, 25-

30 Se desconoce el beneficio que ostentaba Embite, pero la media de las retribuciones de los beneficiados estaba alrededor de las 80£. Carrasco RodrígueZ, Antonio: La ciudad de Orihuela, op. cit., pp. 347-348. En 1556 Embite aparece como ayudante del fabriquero ("arrecador de la fulla"). Archivo Histórico de Orihuela, Libro de fábrica de la catedral de Orihuela (1555-1556), sig. D 319-4, fol. 192r, 26-06-1556.

31 La bula de erección de la catedral fue emitida por el papa Pío IV (Roma, 14 de Julio de 1564) [E-ORI, Bula de Pio IV de creación de la diócesis de Orihuela, 1564, sig. 1114, pergamino 101 (transcrita y editada en CARRASCO RoDRÍGUEZ, Antonio: La ciudad de Orihuela, op. cit., pp. 434-441)]. La nueva estructura, desarrollada posteriormente por los comisarios apostólicos, comprendía seis dignidades (con una canonjía anexa cada una), otras dieciséis canonjías (más la supresa para la Inquisición), los diez beneficios antiguos, dieciséis capellanías de las que cuatro eran de patronato laico y doce de patronato real (una de ellas para el maestro de capilla y otras cuatro para cantores), y otros sirvientes (organista, pertiguero, sochantre y cuatro cantores con beneficio no colativo). E-ORI, Fundamentum Ecclesiae Oriolensis, 1565, sig. 1097 [en adelante citado como Fundamentum], fols., 37r-49v. Las disposiciones sobre el MC, establecidas el 3 de agosto, aparecen en: Íbid, fols. 228r-230v. Véase también CARRASCO RoDRÍGUEZ, Antonio: La ciudad de Orihuela, op. cit., pp. 342-344, 350-370, y Pérez BerNÁ, Juan: La capilla de música, op. cit., pp. $130-141$. 
coincidieron en que entre el personal de la colegiata había un número indeterminado de cantores. Curiosamente, sólo el fabriquero señaló la existencia de un $\mathrm{MC}^{32}$.

El segundo documento, el informe de la ejecución de las bulas de fundación de la catedral, realizado en 1565 por los comisarios apostólicos Francisco Juan Roca y Miguel Vic, es mucho más explícito. Aporta información precisa sobre las rentas de la colegiata y los emolumentos de algunos de los miembros de la capilla musical (así como sobre las nuevas retribuciones) ${ }^{33}$. La colegiata disponía de una mesa de $3.113 £$ y 10 s, distribuida en dos partidas: $2.602 £, 15$ s y $6 \mathrm{~d}$ para las prebendas y $510 £, 14 \mathrm{~s}$ y $6 \mathrm{~d}$ para gastos $^{34}$. El grupo de los cuatro niños de coro recibía un beneficio simple anual de $20 £$, más $22 £$ de la partida de gastos para su vestido (el beneficio aumentará en 1.564 en $20 £)^{35}$. El organista recibía $50 £$ anuales de la fábrica y cinco cahíces de trigo (a los que se sumarán $10 £$ de la partida de gastos en 1564$)^{36}$. El sochantre cobraba $7 £$ anuales procedente de los gastos de la mesa (su salario no se modificará) ${ }^{37}$. Cada uno de los cuatro cantores contratados habitualmente en la colegiata percibía un sueldo de $25 £$. Estas cuatro plazas se estabilizaron en 1564 y se convirtieron en capellanías menores no colativas y se incluyó un aumento de la mesa de $25 £$ para cada uno ${ }^{38}$. A los nuevos puestos de cantores dotados con capellanías reales se les asignó un beneficio colativo de $80 £$, similar al de los otros capellanes reales ${ }^{39}$.

El informe no indica la retribución que el Mc percibía en la época colegial (en 1564 se establecieron $140 £$, de las que $80 £$ procedían del beneficio de capellán real de la mesa y $60 £$ de la fábrica ${ }^{40}$. Sin embargo, por un nombramiento en 1562 conocemos que "al mestre de capella se acostuma donar sexanta lliures (60£) de salaris de la fabrica" ${ }^{41}$. El nombramiento en cuestión corresponde al MC Pedro

32 E-ORI, Informaciones y averiguaciones hechas por el señor D. Francisco de Castilla, sig. 1121, documento 38, 22-121563. Carrasco Rodríguez, Antonio: La ciudad de Orihuela, op. cit., pp. 171-172.

33 Fundamentum, fols. 199v-226r; CARrasco RodríGuEz, Antonio: La ciudad de Orihuela, op. cit., pp. 294-296, 343.

34 Carrasco Rodríguez, Antonio: La ciudad de Orihuela, op. cit., pp. 347-349. Pérez Berná, Juan: "La capilla de música”, op. cit., pp. 9-10. A. Carrasco utiliza los datos extraídos del Fundamentum, mientras que Pérez Berná se basa en Alenda, Manual para el archivero. Las cantidades varían ligeramente en alguna partida. Se han indicado dichas variaciones en notas a pie de página en cada caso concreto. OJEDA NieTo, José: El patrimonio de la catedral de Orihuela, op. cit., p. 46, cifra las rentas de fábrica en $2.000 £$.

35 Fundamentum, 219v-220v. Carrasco Rodríguez, Antonio: La ciudad de Orihuela, op. cit., pp. 348-349. A. Carrasco confunde datos en esta cuestión. Indica $22 £$ de sueldo (aunque en la tabla de gastos de la colegiata señala correctamente que los $22 £$ son para el vestido) y aumento de $10 £$. En el cómputo total considera sin embargo $10 £$ por cada infantillo (lo que darían los $40 £$ en total).

36 Fundamentum, fol. 219v. Carrasco Rodríguez, Antonio: La ciudad de Orihuela, op. cit., p. 352. Pérez Berná, Juan: La capilla de música, op. cit., p. 74, 131. Aunque Alenda, Manual para el archivero, fol. 20v, especifica claramente que el organista cobraba dicha cantidad en el período colegial, J. Pérez Berná indica que las $50 £$ fueron establecidas en 1565, basándose en CREUs Ortolá, Óscar: Ginés Pérez (1548?-1600): vida y obra. Tesis doctoral; Universitat de València, 2004, p. 54.

37 Fundamentum, fol. 224v. Carrasco Rodríguez, Antonio: La ciudad de Orihuela, op. cit., p. 348, indica esa cantidad bajo la rúbrica "salario de los subcantores".

38 Fundamentum, fol. 220r. Alenda considera que todas las cantidades pertenecían a la fábrica. AlENDA, José: Manual para el archivero, fol. 20r. Carrasco indica el aumento de $100 £$, aunque no la cantidad previa. CARrasco RodríGUEZ, Antonio: La ciudad de Orihuela, op. cit., p. 352.

39 Fundamentum, fol. 216v.

40 Fundamentum, fol. 222r.

41 J. Pérez Berná atribuye a una iniciativa episcopal la creación del puesto de MC, ya que ocurre simultáneamente en otros templos de la diócesis de Cartagena, como Elche, y Albacete. Pérez Berná, Juan: La capilla de música, op. cit., p. 75. Sin embargo, el hecho de que el enunciado diga "que se acostuma" indica seguramente que este cargo existía previamente (véase el apéndice 1). 
Ortega $^{42}$, aunque tradicionalmente se ha afirmado que el documento se refería al MC Ginés Pérez ${ }^{43}$. Las $60 £$ de salario de fábrica se mantendrán a lo largo del siglo XVI, aunque sufrirán variaciones puntuales, señaladas en el apéndice $1^{44}$.

Las modestas retribuciones de los músicos se adaptan a las moderadas rentas de la colegiata de Orihuela, que procedían de los diezmos (incluyendo las tercias reales). La colegiata no tenía apenas propiedades, uno de los conceptos por los que las instituciones religiosas ingresaban mayores cantidades ${ }^{45}$. Además, debido a su deteriorada relación con la catedral de Murcia, las rentas no llegaban en la cantidad y tiempo establecido ${ }^{46}$. Aún así, el salario del MC se sitúa en una franja intermedia entre las colegiatas españolas ${ }^{47}$. Comparada con las colegiatas pertenecientes a la archidiócesis de Valencia, Orihuela es de las mejor dotadas. La similitud con la colegiata de Játiva (también fundada en 1413) es especialmente llamativa ${ }^{48}$.

La ausencia de referencias sobre los ministriles en la etapa colegial en toda la documentación manejada resulta sorprendente. No es hasta 1569 cuando se da a entender que los cuatro ministriles ejercían su oficio en la catedral habitualmente ${ }^{49}$.

El tercer y último documento señalado en la introducción, la "Memoria dels llibres que lo mestre de capella mosen frances joan embite te à son convent" (reproducido en las figuras 1a y 1b y transcrito en la figura 2), contiene información de distinto tipo, referida al repertorio musical de la capilla ${ }^{50}$. Se trata de un inventario de libros de canto de órgano, prestados por el cabildo al Mc mosén Francesc Joan Embite, quien los devolvió en agosto de $1562^{51}$.

42 E-ORI, Actas capitulares, tomo 2 (1554-1568), sig. 870, fols., 96r-97r, 18-10-1562.

43 Esta cuestión es tratada en RodríGuez, Esperanza: Ginés Pérez, op. cit., pp. XXI-XXII.

44 Los salarios derivados de la fábrica volvieron a aumentar en 1588. Al MC se le asignaron $75 £$, al organista $90 £$, al sochantre $20 £$, a los cuatro cantores capellanes reales $65 £, 45 £, 35 £$ y $65 £$ y a los cuatro cantores no beneficiados $70 £, 40 £, 30 £$ y $35 £$. Se incluye por primera vez un salario de $18 £$ para el manchador del órgano. Archivo Histórico de Orihuela, Protocolos notariales, notario Jaume Montiel, sig. 242, 06-09-1588 (transcrito en NieTo, Agustín: Orihuela en sus documentos: la Catedral, Parroquias de Santas Justa y Rufina y Santiago. Murcia, Espigas, 1984, p. 185).

45 Nieto, OjedA, José: El patrimonio de la catedral de Orihuela, op. cit., pp. 39-41. Cuando la colegiata se convirtió en catedral, su nivel de rentas se situó entre las más bajas de la península. SuÁrez-PAJARES, Javier: "Dinero y honor”, op. cit., pp. 193-194.

46 Riera, Juan: Rentas eclesiásticas, moriscos y penitenciados: (los obispados de Cartagena y Orihuela a mediados del siglo XVI). Valladolid, Universidad de Valladolid, Secretaría de Publicaciones, 1984, pp. 9-12.

47 El MC de Logroño recibía unas $84 £$ (30.000 maravedís) y el de Borja unas $48 £$ (17.000 maravedís) más 48 fanegas de cebada. Los datos están tomados de SuÁrez-PajARes, Javier: "Dinero y honor", op. cit., pp. 181-182, quien expresa todas las cantidades en maravedís. Se ha hecho la conversión a libras valencianas para facilitar la comparación (1£=356,25 maravedís).

48 Alberola Verdú, Josep A: La música a la col-legiata de Xàtiva, op. cit., pp. 148-153, 217-218, 238-239.

49 E-ORI, Actas capitulares, tomo 3 (1568-1590), sig. 871, fol. 6r, 27-01-1569.

50 E-ORI, Actas capitulares, tomo 2 (1554-1568), sig. 870, fols. 394v-395r. PÉrez Berná, Juan: La capilla de música, op. cit., p. 813, señala la existencia de este inventario.

51 Entre los estudios sobre inventarios de libros de música en España cabe destacar Ros-FÁBregas, Emilio: "Libros de música en las bibliotecas españolas del siglo XVI (I, II y III)", en Pliegos de Bibliofilia, 15, 16 y 17 (2001-2002), pp. 37-62, 33-46 y 17-54. Véase también DADSON, Trevor: "Libros e instrumentos de música en inventarios post-mortem del Siglo de Oro español: El caso de Don Juan de Borja (1607)", en Pliegos de Bibliofilia, 14 (2001), pp. 3-18; KNIGHTON, Tess: "La circulación de la polifonía europea en el medio urbano: libros impresos de música en la Zaragoza de mediados del siglo xvı”, en BomBi, Andrea; CARreras, Juan José y Marín, Miguel Ángel, eds.: Música y cultura urbana en la Edad Moderna. Valencia, Universitat de València, 2005, pp. 337-349; ID., "Petrucci's Books in Early SixteenthCentury Spain", en: Cattin, Giulio y Dalla Vecchia, Patrizia, eds.: Venezia 1501: Petrucci e la stampa musicale / Venice 1501: Petrucci, Music, Print and Publishing [actas del Convegno internazionale di studi, Venecia 2001]. Venecia, Fondazione Levi, 2005, pp. 623-642; ID., "Libros de canto: The Ownership of Music Books in Zaragoza in the Early Sixteenth Century", en: Fenlon, Iain y KnIGHTON, Tess, eds.: Early Music Printing and Publishing in the Iberian World. Kassel, Edition Reichenberger, 2006, pp. 215-239. 
Figura 1a: Inventario de libros de canto de órgano de la colegiata de Orihuela, E-ORI, sig. 870. Actas capitulares, tomo 2 (1554-1568), fol. 394v.

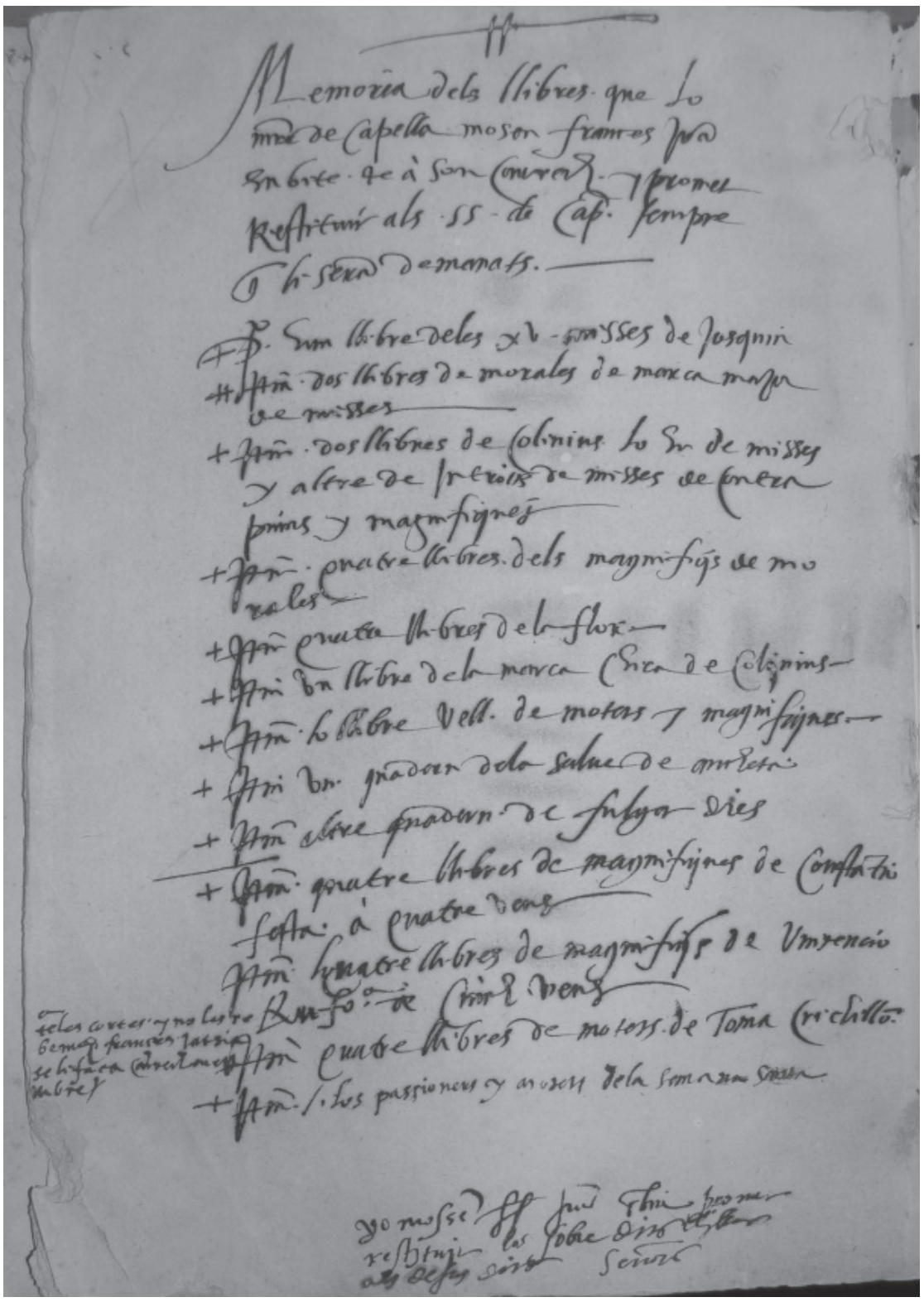

Reproducido con el permiso del Archivo Catedralicio de Orihuela 
Figura 1b: Íbid, fol. 395r

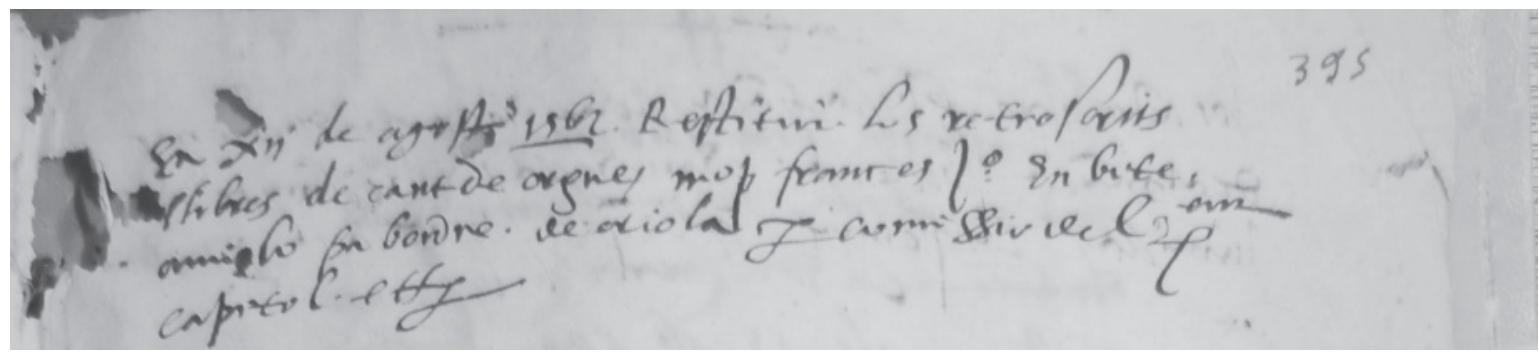

Reproducido con el permiso del Archivo Catedralicio de Orihuela

Tabla 1: transcripción del inventario

[fol. 394v] Memoria dels llibres que lo / mestre de capella mosen frances joan / embite. te à son convent. y promet / restituir als senyors de capítol sempre / que li seran demanats.

[1] primo. hun llibre de les Xv misses de josquin

[2] item. dos llibres de morales de marca major de misses

[3] item. dos llibres de colinius lo hu de misses / y altre de recolls de misses de contra / punts[?] y magnifiques

[4] item. quatre llibres dels magnifiques de mo / rales

[5] item. quatre llibres de la flore

[6] item. un llibre de la marca chica de colinius

[7] item. lo llibre vell de motets y magnifiques

[8] item. un quadern de la salve de ancheta

[9] item. altre quadern de fulget dies

[10] item. quatre llibres de magnifiques de constantio / festa à quatre veus

[11] item. quatre llibres de magnifiques de Vinzencio / Rufo de cinch veus

[12] item. quatre llibres de motets de Toma Crichillon

[13] item. los passioners y motets[?] de la semana santa

[fol. 394v, margen izquierdo]:

a / teles? curtes y no las re / be mossèn frances garsia / se li faca advertencia / ?

[fol. 394v, extremo inferior]:

Yo mossen frances juan embite promet / restituir los sobredits llibres / als desus dits señors

[fol. 395r]:

En xii de agost 1562 restitui los retrobats [?] / llibres de cant de orgue mossèn frances joan enbite / a mi lo pabordre de oriola per comissio del reverend / capitol etcetera. 
El inventario se encuentra en los folios 394v-395r del libro de actas número 2, que comprende el período 1554-1568. Está escrito al final del libro (fol. 394v), tras algunas páginas en blanco. El encabezamiento indica que el MC Embite se compromete a devolver los libros prestados por el cabildo cuando le sean solicitados y a pie de página el propio Embite firma este compromiso.

En la parte superior del fol. 395r, a modo de colofón, el pavorde firma la entrega efectiva de los libros (el resto de la página aparece en blanco). La anotación en el margen izquierdo parece indicar que la devolución a mosén Francesc García (quien probablemente actuó como intermediario entre Embite y el pavorde de la colegiata) no fue completa. Probablemente, los ítems [11] y [12] (a la altura de los cuales está, precisamente, la apostilla) no fueron devueltos, ya que son las únicas entradas que no muestran una cruz a la izquierda.

Conocer las fechas en las que Embite ejerció su magisterio podría ayudar a la datación del inventario. Pero sólo se sabe a ciencia cierta que era MC en 1554 (apéndice 1). El hecho de que Embite tuviera los libros hasta 1562 puede implicar que mantuviese el puesto hasta poco tiempo antes de esa fecha (cuando devuelve los libros ya no es llamado MC). Si ello fue así, su magisterio se habría visto interrumpido al menos una vez en 1556, cuando otro MC (¿Bernardino? de Ribera) aparece en los libros de fábrica. Como se ha indicado, Embite era beneficiado de la catedral, circunstancia que le proporcionaría cierta flexibilidad para ejercer intermitentemente como MC en caso de necesidad. Respecto de la devolución, parece lógico que el capítulo, ante el inminente nombramiento de un nuevo MC (Pedro Ortega), decidiera recuperar los libros.

Aunque resulta imposible determinar con seguridad si los libros son impresos o manuscritos, algunos indicios parecen indicar que muchos de ellos son impresos (véase más adelante). En ese caso, y dado que la lista está escrita por una sola mano, la fecha post quem del inventario sería 1559, fecha de edición de los volúmenes [11] y [12].

La identificación del tipo de libro se basa únicamente en la descripción del inventario, ya que ninguno de los volúmenes parece haber sobrevivido. Tampoco se han localizado inventarios posteriores u otra información adicional sobre la adquisición o copia de los volúmenes. Como regla general, se observa que la descripción de los (posibles) impresos ([1], [2], [3], [4], [5], [10], [11] y [12]) es más detallada que la de los (posibles) manuscritos ([6], [7], [8], [9] y [13]). Además, los volúmenes del primer grupo indican el nombre del autor (excepto el ítem [5] que es una colección y el número [6]), al contrario que los del segundo (la excepción es el número [8], la Salve Regina de Juan de Anchieta, de la que no se conoce ninguna edición impresa). Además, los ítems [1], [2], [4] y [5]) figuran entre los libros impresos más comunes en las bibliotecas musicales del Renacimiento en España ${ }^{52}$. Por último, el formato dado en la descripción coincide con el de los impresos ["llibre" se refiere tanto a libro de coro

52 Knighton, Tess: "Morales in Print: Distribution and Ownership in Renaissance Spain", en: Rees, Owen y Nelson, Bernadette, eds.: Cristóbal de Morales: Sources, Influences, Reception. Woodbridge, Boydell Press, 2007, pp. 161-175, en pp. 161-162. 
("un llibre" o "dos llibres") como a libro de partes ("quatre llibres"); "quadern" identifica un fascículo, probablemente en formato de libro de coro con una sola pieza $]^{53}$. Por todo ello, y como hipótesis de trabajo, desde este punto los libros se consideran impresos o manuscritos tal y como se ha indicado arriba.

El volumen [1] ("hun llibre de les xv misses de josquin") se puede identificar con el Liber quindecim missarum (Roma, Antico, 1516) [RISM 1516 ${ }^{1}$. Este ejemplar, en formato de libro de atril, era conocido en español como "las quince misas de Josquin" (o en catalán, como en este caso, y también en italiano) $)^{54}$, aunque incluye también obras de Brumel, Févin, La Rue, Mouton, Pipelare y Roselli. Este libro de misas a 4 voces aparece frecuentemente en las colecciones musicales españolas del siglo $\mathrm{XVI}^{55}$. El impreso seguía en uso en la colegiata en 1598, al menos como material pedagógico ${ }^{56}$.

La descripción del ítem [2] (“dos llibres de morales de marca major de misses”) se ajusta a los dos impresos de misas de Cristóbal de Morales, [2a] Missarum liber primus y [2b] Missarum liber secundus. Los libros listados pudieron ser ejemplares de la edición de Dorico (Roma, 1544), [RISM M3580] y [RISM M3582], o de las ediciones posteriores de Moderne (Missarum liber primus, Lyon, 1545 [no en RISM] o 1546 [RISM M3581]; Missarum liber secundus, Lyon, 1551/1552 [RISM M3583]). Estos dos libros de atril, que contienen misas de entre 4 y 6 voces, figuran también de forma habitual en los fondos de las bibliotecas españolas del siglo Xvi ${ }^{57}$. En numerosas ocasiones los dos volúmenes aparecen listados juntos ${ }^{58}$. La etiqueta de "marca major", referida al tamaño del papel, no ayuda a la identificación de la edición, ya que la nomenclatura de los formatos de los libros antiguos en España es confusa ${ }^{59}$.

La entrada número [3] ("dos llibres de Colinius lo hu de misses / y altre de recolls de misses de contra / punts? y magnifiques") comprende dos libros de coro de Pierre Colin. El primero, [3a], podría

53 Este formato era bastante común entre la música copiada en la capilla Sixtina y la capilla Julia en el Renacimiento. DEAN, Jeffrey: "The Repertory of the Cappella Giulia in the 1560s", en Journal of the American Musicological Society, 41 (1988), pp. 465-490, en p. 474.

54 El libro aparece referido con este nombre en un inventario de época similar en la Cappella Giulia. J. Dean identifica el libro con el impreso de Antico. Íbid., p. 475.

55 Knighton, Tess: "Morales in Print", op. cit., p. 163. E. Ros-Fábregas indica que el Liber quindecim missarum (Nuremberg: Petreius, 1539) [RISM 1539¹] podría corresponder también a esta descripción. El ítem [1] del inventario de Orihuela no puede ser el impreso de 1539, ya que es un libro de coro, mientras que el ejemplar de Petreius fue impreso como libro de partes. Ros-FÁbregas, Emilio: "Libros de música", op. cit., I, pp. 48-49.

56 En fecha 07-09-1598 hay una entrada en las actas capitulares referida a las obligaciones del MC. Una de ellas indica lo siguiente: 'Y un dia cada setmana fassa pratica cantant les misses de Jusquin perque tots aprenguen les dificultats que y a en cant de orgue'. E-ORI, Actas capitulares, tomo 7 (1569-1608), sig. 875, fols. 109r-110r, 07-09-1598.

57 Los detalles sobre la difusión y comercialización de los libros de Morales pueden consultarse en KNIGHTON, Tess: "Morales in Print", op. cit., especialmente en pp. 162-168.

58 Íbid., p. 168; Dean, Jeffrey: “The Repertory of the Cappella Giulia”, op. cit., p. 474.

59 Los ejemplares de Dorico miden 433 x 285 mm, y los de Moderne 400 x 270 mm (Cusick, Suzanne G.: Valerio Dorico: Music Printer in Sixteenth-Century Rome. Ann Arbor, umi Research Press, 1981, pp. 171-72; Pogue, Samuel F.: Jacques Moderne: Lyons Music Printer of the Sixteenth Century. Ginebra, Droz, 1969, pp. 191-194, 201-203). Según el Directorio ibérico de librerías de antiguo y de ocasión. Madrid, Amuravi, 1992, p. 43, los primeros corresponderían al tamaño "gran folio" (más de 40 cm de altura) y los segundos a "folio mayor" (entre 35 y $40 \mathrm{~cm}$ ). MARTínez DE Sousa, José: Diccionario de bibliología y ciencias afines. Gijón, Trea, 2004, p. 433, considera que el papel de "marca mayor" mide 64 x 44 cm. Los libros de Morales se acercarían al tamaño de "marca" (44 x $32 \mathrm{~cm}$ ) en la lista de J. Martínez de Sousa. 
ser el Liturgicon musicarum duodecim missarum (Lyon, Moderne, 1546) [RISM C3310] ${ }^{60}$, ya que es el único impreso conocido de Colin con misas en formato de libro de coro (además del [3b]). Otra opción sería un volumen facticio (impreso o manuscrito) que contuviera las misas a 4 y 5 voces de Colin editadas por Nicolas du Chemin en Paris en 1556 (Missa ad imitationem moduli "Confitemini”, Missa ad imitationem moduli "In me transierunt", y Missa ad imitationem moduli "Surgens Jesus" [RISM C3312, C3313, C3314] ${ }^{61}$. El segundo volumen, [3b], podría corresponder al Liber octo missarum (Lyon, Moderne, 1541) [RISM C3307]. Contiene ocho misas (4-6 voces), ocho motetes (4-6 voces) (¿los "contrapunts" del inventario?) y ocho magníficats (uno en cada tono, a 4 voces). Una copia de [2b] aparece entre los libros de música de la hermana de Felipe II, la princesa Juana de Austria ${ }^{62}$.

La identificación de los "quatre llibres dels magnifiques de mo / rales", ítem [4], no ofrece duda. Los Magnificats de Morales, al igual que sus misas, fueron extremadamente populares en toda Europa, tal y como lo atestiguan sus numerosas ediciones hasta $1600^{63}$. La edición de Gardano (Venecia, 1545) [RISM M3594] es la primera que incluye los magníficats, de entre 2 y 6 voces, en todos los tonos y tanto para versos pares como impares ${ }^{64}$.

El ítem [5] (quatre llibres de la flor) podría ser una de las cuatro antologías impresas por Jacques Moderne entre 1532 y 1539 con ese nombre ${ }^{65}$. La primera de ellas, el Primus liber cum quator vocibus. Motteti del fiore (Lyon, Moderne, 1532) [RISM 1532 ${ }^{10}$ ], contiene motetes de entre 4 y 6 voces, de diversos autores (Courtois, Domin, Gombert, Hesdin, Lasson, Layolle, Lhéritier, Lupus, Penet, Pieton, Richafort, Sermisy, de Silva, Verdelot y Willaert). También podría tratarse de la primera de las dos antologías de "motetti del fiore" que Gardano editó en 1539 (Fior de Mottetti tratti dalli Mottetti del Fiore. Primus liber cum quatuor vocibus (Venecia, 1539) [RISM 153912]), que se imprimió en cuatro libretes. Hay todavía una tercera posibilidad, ya que Gardano publicó en 1545 otra antología llamada Flos Florum [RISM $1545^{4}$ ], una reimpresión de Primus liber cum quator vocibus de Moderne.

Más compleja es la identificación de la entrada [6] ("un llibre de la marca chica de Colinius"). El enunciado se refiere probablemente a un libro de coro de menor tamaño que los descritos en el

60 Pogue y W. C. Lengefeld señalan que el libro fue impreso en 1556. Pogue, Samuel F.: Jacques Moderne, op. cit., p. 207; Lengefeld, William C.: "Colin, Pierre", en: SAdie, Stanley, ed.: The New Grove Dictionary of Music and Musicians. $2^{\mathrm{a}}$ ed., Londres-Nueva York, Oxford University Press, 2001, 29 vols. [en adelante citado como NGD], vol. 6, 106-07. OuvRARD, Jean-Pierre: "Colin, Pierre", en: Finscher, Ludwig, ed.: Die Musik in Geschichte und Gegenwart. Ed. rev., Kassel y Stuttgart, Bärenreiter, 1994-2007, Personenteil, vol. 4, cols., 1372-1374, indica 1546.

61 Lesure, François y Thibault, Geneviève: "Bibliographie des édition musicales publiées par Nicolas du Chemin (15491576)", en Annales musicologiques, 1 (1953), pp. 269-373, en pp. 316-317.

62 Moll, Jaime: "Libros de música e instrumentos musicales de la princesa Juana de Austria", en Anuario Musical, 20 (1965), pp. 11-23, en 13; Ros-FÁbregas, Emilio: "Libros de música”, op. cit., III, p. 26.

63 Stevenson, Robert: La música en las catedrales españolas del Siglo de Oro. Madrid, Alianza editorial, 1993, p. 21. Citado en Ros-Fábregas, Emilio: "Libros de música", op. cit., I, p. 47. Véase también Ham, Martin: "Worklist", en: Rees, Owen y Nelson, Bernadette, eds.: Cristóbal de Morales, op. cit., pp. 297-393, en pp. 150-151.

64 Knighton, Tess: "Morales in Print", op. cit., p. 169.

65 RISM $1532^{10}, 1532^{11}, 1539^{10}$ y $1539^{11}$. Pogue, Samuel F.: Jacques Moderne, op. cit., pp. 122-133, 145-149. Hay copias de las dos primeras ediciones en la Biblioteca Provincial de Burgos y en la Biblioteca del Real Conservatorio Superior de Música de Madrid. 
ítem [3a] ${ }^{66}$. Tampoco se tiene noticia de otras ediciones dedicadas exclusivamente a la música de Colin anteriores a 1562 en este formato ${ }^{67}$. Cabría, pues, la posibilidad de que se trate de un volumen manuscrito. Podría contener motetes (entre 1539 y 1555 se publicaron quince motetes de Colin en diferentes colecciones $)^{68}$ o misas ${ }^{69}$.

El ítem [7] ("lo llibre vell de motets y magnifiques") parece un libro manuscrito, que debía de contener el repertorio más antiguo de la colegiata.

Las entradas [8] ("un quadern de la salve de ancheta") y [9] ("altre quadern de fulget dies") son los únicos fascículos del inventario. El número [8] se refiere claramente a una copia de la antífona Salve Regina de Juan de Anchieta, conservada en algunos de los más importantes manuscritos españoles de música religiosa ${ }^{70}$. La pieza está escrita en alternatim. Los versos pares son polifónicos a 4 voces (excepto el último que es a 5$)^{71}$.

El ítem [9], Fulget dies, es más difícil de identificar, ya que el título es incompleto ${ }^{72}$. Existen diferentes responsorios y una antífona que comienzan con estas dos palabras, pero cuyo texto y función difieren ${ }^{73}$. Fulget dies hodierna es el único texto sobre el que se ha localizado una única composición polifónica ${ }^{74}$. El texto es apropiado para las celebraciones de la Inmaculada Concepción y la Purificación ${ }^{75}$. Dado que una de las principales advocaciones de la colegiata de Orihuela es la Virgen María, es muy probable que éste sea el texto al que se refiere el ítem [9].

Los “quatre llibres de magnifiques de Constantio / Festa à quatre veus", ítem [10], son con toda probabilidad un ejemplar de Constanzo Festa, Magnificat, tutti gli otto toni, a quatro voce (Venecia, Scotto, 1554) [RISM F642].

66 El Liturgicon mide 400 x $270 \mathrm{~mm}$ y las misas impresas por du Chemin 470 x $310 \mathrm{~mm}$, "folio mayor" y "gran folio" según el Directorio ibérico, op. cit., p. 43. El tamaño exacto de un libro de "marca chica" (o "marca menor") nos es desconocido, ya que la expresión "marca chica" no aparece en J. Martínez de Sousa, Diccionario de bibliología, op. cit., ni tampoco en el Directorio ibérico, op. cit. Un "folio menor" mide de 30 a $33 \mathrm{~cm}$ según el Directorio ibérico, op. cit., p. 43.

67 RISM A/I: Einzeldrucke vor 1800, 9 vols., Kassel, Bärenreiter, 1971-1981, op. cit., vol. 2, p. 182.

68 Lengefeld, William C.: "Colin, Pierre", en NGD, vol. 6, pp. 106-107. El libro de motetes Modulorum (quos vulgo moteta vocant) (París, Nicolas du Chemin, 1561), publicado en formato de libro de partes en 1561 (W. C. Legenfeld indica 1562), resulta un poco tardío para haber sido copiado en Orihuela antes de 1562. Lesure, François y Thibault, Geneviève: "Bibliographie des édition”, op. cit., pp. 331-332.

69 Además de las mencionadas misas, Colin publicó el Liber tertius missae sex (Venecia, Gardano, 1544) [RISM C3308], en formato de libro de partes.

70 Barcelona, Biblioteca de Catalunya, ms. м 454; Sevilla, Biblioteca Colombina, ms. 5-5-20; Tarazona, Archivo Capitular de la Catedral, ms. 2/3; Barcelona, Biblioteca de Catalunya, ms. м 681. KreITner, Kenneth: The Church Music of Fifteenth Century. Woodbridge, Boydell Press, 2004, pp. 123-124.

71 Rubio, Samuel, ed.: Juan de Anchieta. Opera Omnia. San Sebastián, Caja de Ahorros Provincial de Guipúzcoa, 1980, pp. 47-48, 134-151.

72 Quisiera agradecer a Juan Carlos Asensio y a Andy Hulme su ayuda en este apartado.

73 Blume, Clemens y Dreves, Guido M., eds.: Analecta hymnica medii aevi. 55 vols., [original / Leipzig, Fues's Verlag, 1886-1922], Frankfurt, Minerva, 1961.

74 Se trata de un motete de Johannes Mangon contenido en el manuscrito 2 del Archivo Catedralicio de Aquisgrán. Citado en Thомаs, Jennifer: The Motet Database Catalogue Online, <http://www.arts.ufl.edu/motet/default.asp>, [página visitada el 2003-08].

75 Blume, Clemens y Dreves, Guide M., eds.: Analecta hymnica, op. cit., vol. 13, p. 199 y vol. 45b, p. 45. 
La descripción del número [11] ("quatre llibres de magnifiques de Vinzencio / Rufo a cinch veus") parece corresponder a Vincenzo Ruffo, Magnificat... a cinque voci, nuovamente per Antonio Gardano stampati et dati in luce (Venecia, Gardano, 1559) [RISM R3052] ${ }^{76}$. Los magníficats tienen entre 3 y 8 voces $^{77}$.

Los "quatre llibres de motets de Toma Crichillon", número [12], son probablemente un juego de libros de partes del Liber septimus cantionum sacrarum vulgo moteti vocant quatuor vocum (Lovaina, Phalèse, 1559) [RISm C4406] de Thomas Crecquillon. Una copia del impreso se conserva en la Biblioteca del Real Conservatorio Superior de Música de Madrid ${ }^{78}$.

El volumen [13] ("los passioners y motets? de la semana santa”) debía de ser un manuscrito que contenía la música específica para la Semana Santa. Desconocemos a qué motetes se puede referir el enunciado. Tampoco se puede colegir del enunciado si la Pasión seguía el uso romano o el hispano ${ }^{79}$. Pero lo que es seguro es que no se trataba de la Pasión de tipo aragonés, derivada probablemente del modelo italiano de Jan Nasco, e importada a Valencia por Fernando de Aragón, Duque de Calabria ${ }^{80}$.

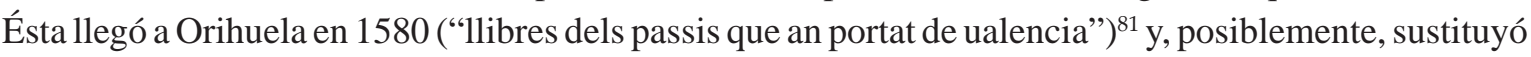
a la nombrada en el inventario. La copia que se conserva actualmente en el archivo es probablemente la que se envió entonces ${ }^{82}$.

Si consideramos que el inventario contiene toda la música polifónica de la colegiata (y es muy probable que así sea, porque parece razonable que el MC tuviese consigo todo el repertorio disponible), podemos obtener una imagen del uso de la polifonía en la colegiata a mitad del siglo xvi. Los géneros mayoritarios son misas, magníficats y motetes. Ello indica que las celebraciones en las que se utilizaba

76 EITNER, Robert: Biographisch-bibliographisches Quellen-Lexikon der Musiker und Musikgelehrten christlicher Zeitrechnung bis Mitte des neunzehnten Jahrhunderts. 11 vols., [original / Leipzig, Breitkopf \& Härtel, 1900-04], Graz, Akademische Druck-u. Verlagsanstalt, 1959-1960, vol. 8, p. 353, señala la existencia de una edición de los magníficats a 5 de Ruffo, realizada por Gardano en 1539. Lewis, Mary S.: Antonio Gardano, Venetian Music Printer, 1538-69. 2 vols., Nueva YorkLondres, Garland, 1988, 1997, vol. 2, pp. 395-396, indica que la única edición conocida de los magníficats es la de 1559.

77 La descripción indica cuatro libros y composiciones a 5, lo que no es demasiado común. No he podido consultar un ejemplar de esta colección pero, curiosamente, la copia más completa que se conserva (Archivio Capitolare de Castell'Arquato) tiene sólo cuatro libros de partes (САтв). Lewis, Mary S.: Antonio Gardano, op. cit., vol. 2, pp. 395-396, indica que esta copia es un ejemplar incompleto. Nueve magníficats manuscritos a 5 y 6 voces se hallan en Tarazona, Archivo Capitular de la Catedral, ms. 9, aunque desconozco si son concordantes con el impreso. Ruiz, Julián; Mosquera, José A. y Sevillano, Justo: Biblioteca de la Iglesia Catedral de Tarazona. Catálogo de libros manuscritos, incunables y de música. Zaragoza, Institución "Fernando el Católico", 1984, p. 121.

78 HAm, Martin: "Crecquillon, Thomasc, en NGD, vol. 6, pp. 653-57, en p. 654, sugiere que la estancia del compositor en España entre 1541 y 1543 al servicio de Carlos v ayudó a la distribución de su música en el país.

79 Sobre la pasión en España, véase GonZÁlez VAlLe, José Vicente: La tradición del canto litúrgico de la Pasión en España: estudio sobre las composiciones monódicas y polifónicas del 'cantus passionis' en las catedrales de Aragón y Castilla, Barcelona, Csic, Monumentos de la Música Española 49, 1992; SNow, Robert: A New-World Collection of Polyphony for Holy Week and the Salve Service: Guatemala City, Cathedral Archive, Music ms 4. Chicago-Londres, University of Chicago Press, Monuments of Renaissance Music 9, 1996, pp. 39-45.

80 FISCHER, Kurt von: "Passion, 1-4", en NGD, vol. 19, pp. 200-207, en pp. 205-206.

81 E-ORI, Actas capitulares, tomo 7 (1569-1608), sig. 875, fol. 57v, 06-03-1580.

82 Orihuela, Archivo de la Catedral, ms. 9. Climent, José: Fondos musicales de la Región Valenciana. Vol. 4, op. cit., p. 22. G. Olson considera que el ejemplar data del inicio del siglo XVII. Olson, Greta: "An Italian Passion in Spain", en BoucKAERT, Bruno; y Schreurs, Eugeen, eds.: Yearbook of the Alamire Foundation 4 [actas del coloquio "Chant and Polyphony", Lovaina, Alamire Music Publishers, 1998], pp. 413-432, en p. 418. 
música polifónica eran, principalmente, misas y vísperas. En ellas, la polifonía sólo suponía una pequeña parte (el ordinario de las misas, y los magníficats de las vísperas). Los motetes se utilizarían en secciones del propio de la misa, en los oficios y, posiblemente, en ceremonias devocionales y procesiones ${ }^{83}$. Sorprende la ausencia de salmos e himnos en el repertorio, que completarían el repertorio básico de una institución como la colegiata oriolana. La existencia de "lo llibre vell de motets y magnifiques" así como del Liber quindecim missarum, que pudo comprarse a principio de siglo, indican que los géneros utilizados no cambiaron sustancialmente desde su introducción ${ }^{84}$. Otras ocasiones especiales en las que la polifonía hacía su aparición eran la Semana Santa y la Salve. En el primer caso, se cantaba en polifonía la Pasión y también algunos motetes. En la ceremonia de la Salve, la antífona Salve Regina ${ }^{85}$ J. de Anchieta figuraba entre el repertorio polifónico. La función del Fulget dies es más difícil de determinar. El servicio de la Salve, cuya estructura se estableció en toda la cristiandad desde finales del siglo xv, incluía oraciones, responsorios y antífonas $^{86}$. La temática mariana de Fulget dies permitiría su inclusión en esta ceremonia, aunque también es posible que se utilizase en otra ceremonia desconocida por el momento. Lo que sí parece claro es que se debió de utilizar en un contexto procesional, sugerido por el formato en el que fue copiado ${ }^{87}$.

En cuanto al tamaño de la capilla, ésta debía de contar con, al menos, cuatro cantores. No se puede descartar que fueran más, dado el considerable número de piezas escritas a 6 voces y algunas a 8 (aunque la existencia del repertorio no implica necesariamente su interpretación). Pero, sobre todo, no hay que olvidar que, en 1564, se dotaron ocho plazas fijas de cantores.

El elevado número de impresos frente al de manuscritos en el listado es llamativo ${ }^{88}$. En este sentido, el inventario oriolano parece separarse del patrón que comienza a emerger del estudio de los inventarios de las instituciones religiosas españolas, en el que manuscritos e impresos guardan una proporción más equilibrada ${ }^{89}$. Parece evidente que la modesta dotación de la colegiata debió de ser un factor determinante para la adquisición de un repertorio estándar: si bien tenía el inconveniente de que no se ajustaba exactamente al ritual específico de la capilla, ofrecía la ventaja de la disponibilidad (más o menos) inmediata.

Independientemente del motivo por el cual el número de impresos en el inventario es tan elevado, lo que se extrae del mismo es la constatación de que la circulación en la península de libros musicales impresos fuera de España era un fenómeno habitual. Al menos, lo suficiente para permitir que una

83 Cummings, Anthony: "Toward an Interpretation of the Sixteenth-Century Motet", en Journal of the American Musicological Society, 34 (1981), pp. 43-59.

84 Con los datos disponibles es imposible señalar cuándo se adquirieron los volúmenes. Además, como indica KNIGHTON, TEss: "Morales in Print", op. cit., pp. 171-172, ciertos libros aún estaban a la venta más de 50 años después de su impresión, bien nuevos o de segunda mano.

85 Antes de la reforma tridentina, esta antífona era utilizada en algunas catedrales españolas de forma exclusiva para finalizar las completas durante todo el año, sin la rotación anual con las otras tres antífonas marianas. Cabe la posibilidad de que fuese interpretada en ese contexto. SNow, Robert J.: A New-World Collection of Polyphony, op. cit., pp. 65-67.

86 Íbid., p. 73.

87 No parece que el uso de este formato obedezca a cuestiones de transmisión de repertorio, como las que indica HAMm, Charles: "Manuscript Structure in the Dufay Era", en Acta musicologica, 34 (1962), pp. 166-184.

88 Véase, por ejemplo, el contenido del inventario de la catedral de Zaragoza en 1546. Knighton, Tess: "La circulación de la polifonía", op. cit., pp. 340-341.

89 Íbid., p. 346. 
institución con una dotación económica limitada y situada lejos de centros de distribución tuviera en su haber libros publicados en Roma, Lyon, Venecia y Lovaina. Según indica T. Knighton, desde los años 30 a los años 60, la mayoría de los libros extranjeros que llegaban a España procedían de Lyon ${ }^{90}$. Barcelona era un centro de distribución de primer orden, que proveía de libros a la zona oriental de la península91. Murcia, situada a veintidós kilómetros de Orihuela, tenía un comercio mucho más modesto. Aún así, en el inventario post-mortem (1615) del librero murciano Juan Dorado se encuentran libros procedentes de Amberes, Venecia, Madrid y Valencia ${ }^{92}$.

Bien sea utilizando los cauces comerciales (a través de Barcelona o Murcia) o mediante compras personalizadas ${ }^{93}$ (miembros de la colegiata viajaron con asiduidad a Madrid y Roma durante el pleito del obispado), es importante señalar la eficiencia del sistema: los impresos de Crecquillon y Ruffo, publicados en 1559, estaban en poder del MC antes de 1562, cuando se devolvieron los libros al cabildo.

La consecuencia inmediata de la adquisición de libros impresos es la amplia procedencia geográfica del repertorio de la colegiata. Aún considerando que todos los manuscritos sin atribución del inventario tuvieran música española, la proporción de música internacional (y posiblemente podríamos incluir a Morales en este apartado, tanto por su trayectoria como por el lugar de publicación de sus impresos) es mucho mayor. La presencia de la música franco-flamenca en el siglo XVI en España ha sido ya señalada por diversos autores ${ }^{94}$. El inventario muestra, además, la importancia de autores franceses de la generación posterior a Josquin, como Colin, y de italianos como Festa y Ruffo.

\section{Conclusiones}

La práctica de la música polifónica en la colegiata de Orihuela se remonta a su fundación en 1413, cuando se instituyó el uso de polifonía en las celebraciones de la octava del Corpus. La presencia de maestros de capilla desde, probablemente, los años 30 del siglo XVI presupone la existencia de una

90 Knighton, Tess: "Petrucci's Books", op. cit., p. 628.

91 Íbid., p. 637.

92 Dadson, Trevor: Libros, lectores y lecturas: Estudios sobre bibliotecas particulares españolas del Siglo de Oro. Madrid, Arco libros, 1998, pp. 33-34.

93 RuIz DE Linory, José: La música en Valencia: diccionario biográfico y crítico, [original / Valencia: Establecimiento Tipográfico Domènech, 1903], facsímil / Valencia, Librerías "París-Valencia", 1987, p. 400, señala que en 1506 un clérigo valenciano volvió de Roma a su ciudad natal con 28 libros de polifonía que él mismo había adquirido. Citado en KNIGHTON, Tess: "Libros de canto", op. cit., p. 231.

94 Aunque la existencia de música franco-flamenca en la península era conocida de antaño, recientes estudios coinciden en señalar una mayor presencia de la que se podría inferir a partir de las fuentes musicales conservadas. KNIGHTON, Tess: "Transmisión, difusión y recepción de la polifonía franco-neerlandesa en el reino de Aragón a principios del siglo Xvi”, en Artigrama, 12 (199697), pp. 19-38; WagstafF, Grayson: “Mary’s Own. Josquin's Five-Part Salve regina and Marian Devotions in Spain”, en Tijdschrift van de Koninklijke Vereniging voor Nederlandse Muziekgeschiedenis, 52 (2002), pp. 3-34; Ros FáBregas, Emilio: "Música y músicos "extranjeros" en la España del siglo xvi", en: CARreras, Juan José y García García, Bernardo, eds.: La Capilla Real de los Austrias, op. cit., pp. 101-126; ID.: "Libros de música", op. cit., I, pp. 48-50. Las dos últimas publicaciones se ocupan también de la valoración e implicaciones historiográficas del pretendido aislamiento de la música española en esta época. 
capilla, indicio que confirman los pagos realizados a cantores, maestros de capilla y organistas en los años 50. Los informes de los años 60 apuntan a una capilla consolidada. Las retribuciones corresponden al nivel económico de la colegiata y a su posición jerárquica en el entramado de la archidiócesis valenciana. Destaca la similitud de las condiciones ofrecidas por las colegiatas de Orihuela y Játiva.

Según se desprende del inventario de música polifónica que la colegiata tenía a mitad del siglo XVI, el repertorio consistía en misas, motetes y magníficats, así como música para la Semana Santa y la ceremonia de la Salve. También se puede inferir del inventario que la capilla debía de estar integrada por, al menos, cuatro cantores, aunque seguramente serían más.

El elevado número de impresos de procedencia extranjera en el inventario, sugiere que la distribución de este tipo de libros en España es más amplia de lo que los escasos ejemplares conservados permiten suponer. Ello es más evidente al tratarse del inventario de una modesta institución con medios exiguos, situada fuera de los circuitos principales de distribución. El hecho de que la colegiata no tuviera apenas libros manuscritos (lo que distingue el inventario de otros conservados en diferentes instituciones) fue probablemente derivado de la escasa dotación de la colegiata.

La procedencia del repertorio viene determinada por el gran número de libros impresos. Como consecuencia del origen extranjero de los mismos, la música disponible en la colegiata de Orihuela a mitad del siglo XVI muestra una elevada proporción de música flamenca, francesa e italiana (incluimos aquí la música de Morales, impresa en Italia). La única música de la que se puede afirmar su origen español es la Salve Regina J. de Anchieta. Sin embargo, el repertorio de los manuscritos con música adaptada a la liturgia local (como el repertorio de la Semana Santa y la Salve) y del libro antiguo de motetes y magníficats podrían ser también de origen autóctono.

\section{APÉNDICE}

\section{Noticias sobre maestros de capilla ${ }^{95}$.}

1. Pedro de Ribera (MC antes de 1535): fue MC de la Colegiata de Orihuela poco después del nacimiento de su hijo, Bernardino de Ribera (véase más adelante) ${ }^{96}$. Había sido infantillo en la catedral de Sevilla y MC de la colegiata de Játiva ${ }^{97}$. Se trasladó posteriormente a la catedral de Murcia, donde se

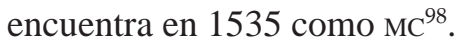

95 Pérez Berná, Juan: La capilla de música, op. cit., pp. 813-814, incluye una lista preliminar de maestros de capilla, que se amplía en este apéndice. datos.

96 Noone, Michael: 'Ribera, Bernardino de', en $D M E H$, vol. 9, pp. 171-172. M. Noone no señala de dónde extrae los

97 Reynaud, François: La polyphonie tolédane, op. cit., p. 123.

98 Prats Redondo, Consuelo: "Murcia", en $D M E H$, vol. 7, pp. 889-896, en p. 893. 
2. Francesc Joan Embite (MC en 1554): ${ }^{99}$ se tiene constancia de que era MC en 1554 y que ocupaba un beneficio en la catedral. La siguiente noticia sobre este MC aparece en el inventario de libros realizado antes de 1562, también mencionado. Allí se le cita como Francesc Joan Embite. Se indica también que era beneficiado de la catedral y residía en un convento. Entregó los libros el 12 de agosto de ese año, cuando ya no se le nombra como Mc. La fecha de finalización de su maestría es desconocida.

3. Bernardino? de Ribera (MC en 1556): en el libro de fábrica de 1556 aparece un pago a "mossèn Ribera mestre de capella"100. La fecha parece demasiado tardía para corresponder a Pedro de Ribera. Aunque pudo recibir órdenes eclesiásticas no es lo más probable, ya que era casado y con hijos. Sin embargo la fecha y el estado eclesiástico se ajustan bien al perfil de su hijo Bernardino. Parece probable que éste comenzase su trayectoria como Mc en una colegiata en la que había sido previamente infantillo y su padre MC. Posteriormente, sería nombrado mC en Ávila (1559-1562), Toledo (1563-1570) y Murcia $(1571-1580)^{101}$.

Por el expediente de limpieza de sangre de Bernardino realizado por la catedral de Toledo en 1563, conocemos su lugar de nacimiento (Játiva), así como los nombres y orígenes de sus antepasados ${ }^{102}$. Hay datos contradictorios sobre los años inmediatamente posteriores. Mientras que el expediente indica que el niño y su madre vivieron con sus abuelos en Játiva y que Bernardino fue uno de los primeros alumnos de Jayme López, ${ }^{103} \mathrm{M}$. Noone afirma que toda la familia se fue a Orihuela al poco de nacer Bernardino $^{104}$. Independientemente de dónde pasara sus primeros años, no parece haber obstáculo para que fuese infantillo en Játiva y poco después en Orihuela. Según M. Noone, la familia se trasladó después a Murcia, donde el padre fue Mc. Esta vinculación de Bernardino con Murcia pudo pesar en su retorno, ahora como Mc, tras su paso por Ávila y Toledo.

4. Pedro Ortega (MC en 1562-después de 1564): su nombramiento como MC se produjo el 18 de octubre de 1562 con un salario de $60 £$, tal y como se ha indicado anteriormente. Esta fecha se conocía desde 1895, cuando Julio Blasco y Felipe Pedrell publicaron la existencia del acta capitular en su estudio sobre Ginés Pérez ${ }^{105}$. Sin embargo, adscribieron el nombramiento a Pérez en lugar de a Ortega, y así se ha venido repitiendo hasta fecha reciente ${ }^{106}$. El acta capitular habla de un proceso de selección complejo, ya que la oposición fue ganada en primer lugar por Cristóbal Cortés ${ }^{107}$, candidato que fue

99 J. Pérez Berná identifica a este maestro de capilla como "Mestre Mossén Francés" y sugiere una posible relación entre este maestro de capilla y los cantores franceses de la catedral de Murcia. Pérez Berná, Juan: La capilla de música, op. cit., p. 813. 1556.

100 Archivo Histórico de Orihuela, Libro de fábrica de la catedral de Orihuela (1555-1556), sig. D 319-4, 192v, 26-06-

101 Prats Redondo, Consuelo: "Murcia”, en $D M E H$, vol. 7, pp. 889-896, en p. 893.

102 Reynaud, François: La polyphonie tolédane, op. cit., pp. 122-123.

103 Según Alberola Verdú, José A.: La música a la col-legiata de Xàtiva, op. cit., pp. 134, 158-159, Jaume Llopis fue mc de la colegiata de Játiva desde una fecha desconocida (pero posterior a 1545, cuando el MC es Joan Giner) hasta 1566.

104 Noone, Michael: "Ribera, Bernardino de", en $D M E H$, vol. 9, pp. 171-172.

105 Blasco, Julio y Pedrell, Felipe: "Juan Ginés Pérez", op. cit., p. vi.

106 Climent, José: "Pérez de la Parra, Ginés", en $D M E H$, vol. 8, p. 641; Creus Ortolá, Óscar: "Ginés Pérez", op. cit., pp. 71-72; Pérez BeRnÁ, Juan: La capilla de música, op. cit., pp. 75, 814.

107 Cristóbal Cortés, quién probablemente procedía de Castilla, fue MC de la iglesia del Pilar de Zaragoza desde 1577 
rechazado posteriormente en beneficio de Ortega. El documento refleja la división del cabildo en dos secciones enfrentadas por su apoyo a los distintos candidatos, aunque no entra en detalles sobre las causas para apoyar a uno u otro ${ }^{108}$.

Ortega era todavía era MC en 1564, tal y como consta en el libro llamado Contestador de la catedral de Orihuela ${ }^{109}$. Posteriormente ejerció su cargo en Sigüenza (1568-1579) ${ }^{110}$, la capilla de las Descalzas Reales de Madrid (1579-1580) ${ }^{111}$ y Murcia (1580-1610) $)^{112}$.

5. Ginés Pérez de la Parra (¿1566?-1582): posiblemente sucedió a P. Ortega, aunque se desconoce la fecha exacta de su nombramiento. Es muy probable que fuese nombrado Mc tras la creación del cargo el 3 de agosto de 1565 o en enero de 1566, cuando la estructura catedralicia se hizo efectiva. Seguramente se le asignaron las $140 £$ ( 80 de beneficio y 60 de salario de fábrica) establecidas en el informe de aplicación de las bulas mencionado anteriormente. Fue investido capellán real en mayo de 1566, siendo ya $\mathrm{MC}^{113}$. Desde 1581 ejerció como MC en la catedral de Valencia hasta su vuelta en 1595 a Orihuela como canónigo de la catedral ${ }^{114}$.

6. ? (1582-1585?): tras la marcha de Pérez, hay un nombramiento de un MC en mayo de $1582^{115}$. No se indica nombre alguno y sólo se señala que el individuo residía en Zaragoza. Se le asigna una retribución total de $150 £, 100$ de fábrica y 50 de la capellanía. El cabildo decidió pagarle el sueldo desde que salió de Zaragoza, y le concedió el honor de llevar las insignias de los teólogos. Además le permitió no asistir a los oficios cuando estuviese ocupado en la composición ${ }^{116}$. En 1585 al cabildo acordó nombrar abogados para la causa que se seguía contra el MC, sin indicar otras circunstancias del asunto $^{117}$.

hasta su muerte en 1594, como indica CALAHORRA, Pedro: Historia de la Música en Aragón: siglos I-XVII. Zaragoza, Librería General, 1977, p. 76. F. Pedrell señala que el cabildo estaba muy complacido con su trabajo y también que fue "condiscípulo del maestro oriolano Juan Ginés Pérez", sin aclarar el significado exacto de dicha afirmación. Pedrell, Felipe: Diccionario biográfico y bibliográfico de músicos españoles. Barcelona, Imprenta de Víctor Berdós y Feliu, 1894-1897, p. 420.

108 Rodríguez, Esperanza: Ginés Pérez, op. cit., pp. XXI-XXII.

109 Se le cita como correo de una carta que envió una delegación oriolana desde la corte en Madrid a Orihuela en mayo de 1564. Archivo Municipal de Orihuela, sig. A-72, Contestador, 16-07-1564, fols. 627r-v, en 627v.

110 Jambou, Louis: "La capilla de música de la Catedral de Sigüenza en el siglo XVI. Ordenación del tiempo musical litúrgico", en Revista de Musicología, 6 (1983), pp. 271-298, en p. 280.

111 Mota Murillo, Rafael: Sebastián López de Velasco (1584-1659). Libros de misas, motetes, salmos, magnificats y otras cosas tocantes al culto. Vol. I: Estudio biográfico, histórico y analítico. Madrid, Sociedad Española de Musicología, 1980, pp. 48-49, indica que Ortega fue nombrado capellán contralto en 1579, sin que se sepa cuándo accedió al puesto de MC. En 1581, cuando Ginés de Pineda fue nombrado mC, Ortega ya había abandonado la institución. Véase también Olmos SáEz, Ángel Manuel: "Aportaciones a la temprana historia musical de la capilla de las Descalzas Reales de Madrid (1576-1618)", en Revista de Musicología, 26 (2003), pp. 439-490; Ruiz Tarazona, Andrés: "Descalzas Reales", en DMEH, vol. 4, p. 457; CAPDEPÓN VERDú, Paulino: "La Capilla Musical de las Descalzas Reales", en Anales del Instituto de Estudios Madrileños, 37 (1997), pp. $215-26$.

112 Prats Redondo, Consuelo: "Murcia", en $D M E H$, vol. 7, pp. 889-896, 893.

113 Archivo Histórico de Orihuela, Protocolos notariales, notario Pedro Conesa, sig. 96, 30-05-1567. PéREz BERnÁ, Juan: La capilla de música, op. cit., p. 814, indica el año 1575.

114 Rodríguez, Esperanza: Ginés Pérez, op. cit., pp. XXI-XXIV. Garzón.

115 Pérez Berná, Juan: La capilla de música, op. cit., p. 814, considera que el nombramiento recayó en Juan Fernández

116 E-ORI, Actas capitulares, tomo 7 (1569-1608), sig. 875, fols. 66v-67r, 16-05-1582.

117 E-ORI, Actas capitulares, tomo 7 (1569-1608), sig. 875, fol. 74r, 05-06-1585. 
7. Juan Fernández Garzón (antes de 1588-1591): el nombre de "mosén Juan Garzón” se ha localizado por primera vez en un acta de agosto de 1588, donde se acuerdan las obligaciones del $\mathrm{MC}^{118}$. Este dato, junto con la subida de sueldo del MC en septiembre de 1588 (véase nota al pie 44), parece indicar que Fernández Garzón estaba recién llegado. Tras la marcha del anterior Mc en fecha desconocida, las $100 £$ de fábrica debieron de rebajarse a las $60 £$ establecidas en la fundación de la catedral. Tras la subida a $75 £$ en 1588 , el salario de fábrica se mantuvo hasta, al menos 1591 . Esto es lo que tenía asignado Juan Fernández Garzón (como se le nombra en el libro de fábrica), ya que en noviembre de ese año recibió $25 £$ como primera tercia de su salario anual (tercia cumplida el 24 de octubre) ${ }^{119}$. Natural de Baeza, Jaén, aparece como MC de la catedral de su ciudad natal entre 1591 (debió de llegar en diciembre) y 1597 (como sucesor de su padre Diego en el cargo). En 1597 se trasladó a Murcia donde había sido nombrado racionero y $\mathrm{MC}^{120}$.

7. Diego Herrera (?-1609): se desconoce cuándo fue nombrado MC, aunque es posible que ocupara el cargo en 1591 tras la marcha del anterior MC. El primer documento con su nombre aparece en 1600, cuando se le impone una multa por un motivo no aclarado ${ }^{121}$. Tras su muerte en 1608, conocemos que el salario de fábrica había vuelto a las $60 £$ (ésta es la cantidad que se reparten los cantores que ejercen las funciones del MC) $)^{122}$. La situación de interinidad se prolongó hasta el nombramiento de Vicente García como nuevo MC en $1610^{123}$.

Recibido: 08/05/2008

Aceptado: 28/10/2008

118 E-ORI, Actas capitulares, tomo 7 (1569-1608), sig. 875, fol. 81v, 22-08-1588. 24-11-1591.

119 Archivo Histórico de Orihuela, Libro de fábrica de la catedral de Orihuela (1591-1592), sig. 1085, fols. 30v-31r,

120 Jiménez Cavallé, Pedro: "Fernández Garzón, Juan”, en $D M E H$, vol. 5, p. 67. Sin embargo, Prats Redondo, Consuelo: "Murcia", en $D M E H$, vol. 7, pp. 889-896, en p. 893, indica que Pedro Ortega fue MC desde 1580 hasta 1616, sin hacer mención a Fernández Garzón.

121 E-ORI, Actas capitulares, tomo 7 (1569-1608), sig. 875, fol. 113v, 27-04-1600.

122 E-ORI, Actas capitulares, tomo 7 (1569-1608), sig. 875, fol. 14, 16-04-1608; E-ORI, Actas capitulares, tomo 8 (16091625), sig. 876, fols. 13v-14r, 30-03-1609. PérEz BERNÁ, Juan: La capilla de música, op. cit., p. 814.

123 E-ORI, Actas capitulares, tomo 8 (1609-1625), sig. 876, fol. 48r, 16-05-1610. 